\title{
Management of the unexpected result: compensated hypothyroidism
}

\author{
Rafn Benediktsson, Anthony D Toft
}

\begin{abstract}
Summary
The combination of elevated serum thyrotropin and normal serum thyroxine is called compensated or subclinical hypothyroidism. This most commonly represents clinically silent autoimmune thyroiditis. Whether this condition warrants treatment or simply observation is still debated. The risk of developing overt hypothyroidism is high in females with elevated thyrotropin above $10 \mathrm{mU} / \mathrm{l}$ and/or positive thyroid microsomal antibodies. Males are also at high risk of progression towards overt hypothyroidism, regardless of antibody status or degree of thyrotropin elevation. We advise routine treatment of only those at high risk of developing overt hypothyroidism.
\end{abstract}

Keywords: hypothyroidism

The term compensated hypothyroidism $(\mathrm{CH})$ is used to describe a specific combination of thyroid function tests, namely a raised serum thyrotropin (TSH) concentration (usually between 3.5 and $20 \mathrm{mU} / \mathrm{l}$ ) in association with normal serum thyroxine (T4). Some authorities include absence of symptoms in their definition of compensated hypothyroidism, hence the more commonly used synonym, subclinical hypothyroidism.

The recognised causes of $\mathrm{CH}$ are listed in box 1. In day-to-day practice this pattern of thyroid function tests is most frequently apparently idiopathic, having been unveiled during the search for disease in individuals with vague non-specific complaints such as tiredness and lethargy. Overt hypothyroidism may or may not have been a relevant differential diagnosis, but ticking the box for thyroid function tests on the laboratory request form is increasingly practised. Although overt hypothyroidism is not uncommon in the general population (prevalence in UK women $1.4 \%$ but $<0.1 \%$ in men), about eight cases of $\mathrm{CH}$ will be turned up for each case of overt hypothyroidism. ${ }^{1}$ It is therefore clear that injudicious use of relatively cheap thyroid function tests may cause problems unless there is a clear idea beforehand about what to do with the result.

\section{Management}

It is easy to deal with patients with a raised serum TSH due to inadequate thyroxine replacement in previously diagnosed overt hypothyroidism. Similarly, no one doubts the validity of thyroxine treatment in individuals with a raised serum TSH concentration on an inexorable course towards overt hypothyroidism, eg, beyond 2 years following surgery or radio-iodine treatment for hyperthyroidism. ${ }^{2}$ Hypothyroidism and $\mathrm{CH}$ are well recognised in association with the use of certain drugs (box 2 ). In these cases, management should be individualised and of course the need to continue the offending treatment must be considered. Common sense suggests that, if there is any suggestion of symptoms or signs potentially attributable to hypothyroidism, the patient should be treated with thyroxine if the offending drug cannot be discontinued or the dose adjusted. After all, the condition is iatrogenic and represents deviation from normal physiology for that individual; TSH secretion is finely tuned with only a $10-20 \%$ fall in usual serum thyroxine levels triggering compensation. Occasionally, a raised TSH is seen in elderly individuals recovering from mild non-thyroidal illness, the clue being in the history. It is, however, less clear what to do in the case of apparently idiopathic $\mathrm{CH}$.

\section{Prevalence in iodine-replete elderly women}

The term compensated hypothyroidism implies primary failure of the thyroid gland as the initiating pathophysiology. The hypothalamus

\begin{tabular}{|l|}
\hline $\begin{array}{l}\text { Causes of compensated } \\
\text { hypothyroidism }\end{array}$ \\
\hline autoimmune thyroiditis \\
- inadequate thyroxine replacement \\
- surgery for thyrotoxicosis \\
- drugsiodine treatment for thyrotoxicosis \\
\hline
\end{tabular}

Box 1

\begin{tabular}{|l|}
\hline Medication that may cause \\
hypothyroidism \\
\hline amiodarone \\
- iodine \\
antithyroid drugs \\
- lithium \\
\hline
\end{tabular}

Box 2 
and pituitary gland supposedly compensate by increasing TSH secretion. Most authorities believe that the underlying pathology is indeed autoimmune thyroiditis (ie, either preclinical Hashimoto's disease or atrophic thyroiditis) with slow ongoing destruction of the gland. The evidence for the autoimmune hypothesis is mostly indirect and derived from numerous cross-sectional epidemiology studies from various parts of the world. ${ }^{13-6}$ However, some good supportive evidence was produced with the identification of certain strong risk factors for progression to overt hypothyroidism in the 20 year follow-up of the Whickham survey. ${ }^{7}$ Overall, these studies support the hypothesis of an early immune attack on the thyroid, perhaps due to molecular mimicry involving gut bacterial antigens. ${ }^{8}$ There is an initial thyroid lymphocytic infiltrate which is then followed by the appearance of thyroid autoantibodies, raised TSH and finally overt hypothyroidism. ${ }^{9}$

Autopsy studies ${ }^{10}$ in iodine-sufficient areas of the world have shown that thyroid autoimmunity, as evidenced by a lymphocytic thyroid infiltrate, is so common in the general population $(45 \%$ of Caucasian females and $20 \%$ of males $>20$ years old) that it could be considered normal. The lymphoid infiltrate is already extensive in teenagers, the extent increasing very little beyond the 20 s until about 70 years of age. ${ }^{10}$ Thyroid microsomal antibodies are directed against thyroid peroxidase (TPO-Ab), the enzyme responsible for iodination of tyrosine in the synthesis of thyroid hormone. This antibody is a very sensitive indicator of thyroid autoimmunity, being positive in at least $95 \%$ of cases of autoimmune hypothyroidism, thus making the measurement of thyroglobulin antibodies superfluous. In keeping with the autopsy studies (and the autoimmune hypothesis), the prevalence of TPO-Ab increases steadily with age (overall $\sim 10 \%$ in women $>18$ years of age $^{1}$ ), being $>30 \%$ in women over 70 years of age. ${ }^{11}$

The Whickham survey looked at a random population sample of some 2779 British individuals who were representative of the general population as regards age, sex and social class. These were studied at baseline ${ }^{1}$ and again after 20 years of follow-up. ${ }^{7}$ Not only did the prevalence of thyroid antibodies increase with age, but so did the prevalence of raised TSH, which overall was $7.5 \%$ in women over 18 years of age and in $2.8 \%$ in men of the same age. This is paralleled by the age-specific incidence of overt hypothyroidism which rarely presents before the age of 45 and peaks around the age of 80 years. $^{7}$ The positive relationship between the extent of TSH elevation in $\mathrm{CH}$ and the prevalence of TPO-Ab can be taken as further supportive evidence for the autoimmune hypothesis. Britain is relatively iodine-sufficient, but it is well recognised that iodine influences thyroid autoimmunity, iodination programmes being accompanied by an increased incidence of clinical thyroid autoimmune diseases. ${ }^{12}$ This was recently illustrated in a Hungarian study of 80 -year-olds ${ }^{13}$ and in a comparative study ${ }^{14}$ of 68-year-olds in Jutland, Denmark (low iodine intake: about $50 \mu \mathrm{g} /$ day) and Iceland (high iodine intake: about $300 \mu \mathrm{g} /$ day), where the prevalence of a raised TSH above $5 \mathrm{mU} / 1$ was $3.4 \%$ in women in Denmark but $20.4 \%$ in Iceland. As expected, this was about four times the male frequency.

\section{Progression to overt hypothyroidism}

There are in fact only two reasons for wishing to detect apparently idiopathic $\mathrm{CH}$. The first would be if symptoms or important signs were shown conclusively to be due to the condition. The other reason, however, would be if overt hypothyroidism were the inevitable outcome. Therefore we must ask how we can identify those at greatest risk of progression.

The very high prevalence and early appearance of thyroid lymphocytic infiltration contrasts with population prevalence of overt hypothyroidism. If the autoimmune hypothesis is true, this must mean that the progression of $\mathrm{CH}$ is extremely slow. Alternatively there is no connection between lymphocytic infiltration, $\mathrm{CH}$ and overt hypothyroidism. In the Whickham survey, ${ }^{7}$ only $33 \%$ of women with $\mathrm{CH}$ (negative antibodies initially) developed overt clinical or biochemical hypothyroidism over 20 years. The progression thus appears to be very slow indeed and it is likely that a number of individuals will succumb to unrelated illnesses before ever reaching the stage of overt hypothyroidism.

One group of investigators has even suggested that a subgroup with $\mathrm{CH}$ will not progress to overt hypothyroidism and that these can be identified by a normal 24-h ${ }^{131}$ I-uptake after either TSH or triiodothyronine (T3) pre-treatment. ${ }^{15}$ The hypothesis is that an isolated insult to the thyroid has reduced the synthetic capacity of the thyroid gland which, however, is able to maintain normal thyroid hormone output in the face of raised TSH (a new setpoint), the patient being "euthyroid with a reset thyrostat". It is of course possible that such a group exists, which then presumably does not have autoimmune hypothyroidism and is at insignificant risk of progression to overt disease. It is important to confirm $\mathrm{CH}$ with a second test at 3-6 months as mildly elevated TSH levels may return to normal and it is known that TPO-Ab disappear in about $10 \%$ of cases. ${ }^{7}$ The role of blocking TSH receptor antibodies in $\mathrm{CH}$ has not been studied, but these have been described in $10-20 \%$ of cases of autoimmune hypothyroidism. ${ }^{16}$

According to the Whickham survey, ${ }^{7}$ the risk of progression to overt hypothyroidism is about five times greater in men than in women and the risk is closely associated with the presence of TPO-Ab and TSH elevation, but not family history or (surprisingly) goitre. The risk of developing overt hypothyroidism increases significantly at levels as low as at $2 \mathrm{mU} / \mathrm{l}$, the 20 -year probability for antibody-negative women being $6 \%$ if initial TSH is $6 \mathrm{mU} / 1$ but rising to $19 \%$ if initial $\mathrm{TSH}$ is $12 \mathrm{mU} / \mathrm{l}$. It is thought ${ }^{9}$ that $80-90 \%$ of women with $\mathrm{TSH}>$ $10 \mathrm{mU} / 1$ have positive thyroid antibodies and these, according to the Whickham study, 
Groups at high risk of progression to overt hypothyroidism

men

- women with positive TPO-Ab, TSH > $10 \mathrm{mU} / 1$, or those previously treated for Graves' disease with surgery or radioiodine

Box 3

significantly influence the risk of progression to overt hypothyroidism. Thus, the odds ratio for a woman developing overt hypothyroidism was eight if she had either positive antibodies alone (95\% confidence interval (CI) 5-15) or raised TSH above $6 \mathrm{mU} / 1$ alone $(95 \% \mathrm{CI} 3-20)$. That equates to about $2.1-2.6 \%$ annual risk, but the odds rise sharply to 38 (95\% CI 22-65) for women with both positive antibodies and raised TSH (4.3\% annual risk).

\section{Benefits of thyroid hormone replacement}

This is a difficult area if not only for the fact that some authors include absence of symptoms in their definition of $\mathrm{CH}$. However, if we believe the autoimmune hypothesis, ie, that $\mathrm{CH}$ represents the earliest stages of thyroid failure, then we should expect to find mild symptoms or at least subtle signs of hypothyroidism if we look closely enough. Obtaining conclusive proof is, however, fraught with difficulties as many of the symptoms associated with hypothyroidism are vague and nonspecific. At the outset, it is therefore important to realise that only very large studies are likely to have the power to demonstrate significant associations. Sadly the literature is full of small uncontrolled inconsistent groups which only serve to cloud the issue.

Two placebo-controlled reports have used symptom scores in an attempt to clarify matters and are often cited as evidence for a benefit associated with thyroid hormone replacement in $\mathrm{CH}$. Cooper and colleagues ${ }^{17}$ studied 32 individuals in a one-year double-blind randomised placebo-controlled trial. The dose of thyroxine was adjusted to keep TSH $\leqslant 3.5$ $\mathrm{mU} / 1$ in the thyroxine group. Symptoms were assessed using a questionnaire on which the symptom score was not statistically different in the two groups at the outset. At the end of the study, total symptom score was not compared again, but rather the change in symptom score, with the authors reporting no change in the placebo group but slight improvement in the thyroxine group. This difference was reported as significant by the authors $(p<0.05)$. Several markers of end-organ thyroid hormone action were also studied. In short, no differences were found and no correlation with improvement in symptoms was observed. There are several weaknesses in this study. The study was small and not pre-powered and a minority of invitations to participate were taken up. Almost all the subjects had previously been hyperthyroid due to Graves' disease, a population characterised by high prevalence of post-treatment dissatisfaction, in particular regarding weight gain, irrespective of post-treatment thyroid status. ${ }^{18}$ We have already suggested above that this subgroup of $\mathrm{CH}$ should be treated regardless of symptoms, as the risk of progression to overt hypothyroidism is very high.

The other placebo-controlled study by Nyström and colleagues ${ }^{19}$ employed a double-blind $2 \times 6$ month cross-over design. Although the numbers were again small, the subjects were randomly selected from a population study on the basis of thyroid biochemistry only. Twenty out of 22 individuals took up the invitation to participate and all received the same daily dose of thyroxine $(150 \mu \mathrm{g})$. Using an arbitrary definition of improvement in three psychometric tests, the authors identified four responders who all correctly identified the treatment period and reported a feeling of improvement whereas only six of 13 non-responders correctly identified the treatment period and five reported a feeling of improvement. Overall, symptoms scores improved significantly during active treatment $(p<0.01)$. No relationship was observed between any biochemical parameters and improvement as defined above and no pre-treatment parameters could be used to identify 'responders'. Unfortunately, we do not know if any of the individuals in the study were rendered subclinically hyperthyroid (suppressed TSH but normal T4), as it is well-known that patients 'feel better' when taking a dose of T4 in excess of that required to normalise serum TSH. ${ }^{20}$

While a number of studies support the above notion that $\mathrm{CH}$ may be associated with impaired cognitive function or even depression, ${ }^{21} 22$ these are small, uncontrolled, observational or unblinded, and further studies are clearly needed before a firm conclusion can be reached. The same applies to the myriad of studies on potential markers of peripheral thyroid hormone action. Although it is not surprising that $\mathrm{CH}$ has been shown to be associated with mild abnormalities in, for example, skeletal muscle lactate and pyruvate production $^{23}$ or systolic time intervals, ${ }^{24}$ not only the association but also improvement with treatment is controversial and therefore it remains difficult to recommend treatment of patients on the basis of such observations alone.

Classic teaching states that overt hypothyroidism is associated with high total and LDL cholesterol, low HDL cholesterol and high prevalence of ischaemic heart disease. A meta-analysis on the effect of thyroid replacement on lipids in subclinical and overt hypothyroidism was recently published. ${ }^{25}$ The authors reviewed 148 studies published between 1976 and 1996. The conclusion was that normalisation of TSH (and not suppression) in $\mathrm{CH}$ resulted in a reduction of total cholesterol by $0.4 \mathrm{mmol} / 1(95 \% \mathrm{CI} 0.2-0.6 \mathrm{mmol} / \mathrm{l})$. The effect on HDL cholesterol was inconsistent. While the effect on total cholesterol was independent of the initial cholesterol level (a mild abnormality as expected in the first place), the effect in overt hypothyroidism was not only slightly greater, but dependent on the 
initial cholesterol level. Thus, if initial cholesterol was $<8 \mathrm{mmol} / \mathrm{l}$, the reduction with thyroxine replacement was $1.2 \mathrm{mmol} / 1$ (95\% CI $0.9-1.5 \mathrm{mmol} / \mathrm{l})$, but with initial cholesterol above $8 \mathrm{mmol} / \mathrm{l}$ the reduction achieved was 3.4 $\mathrm{mmol} / 1$ (95\% CI 3.0-3.7 mmol/1). The cholesterol reduction achieved in $\mathrm{CH}$ is minimal in the era of HMG-CoA reductase inhibitors (statins) and, in the absence of evidence and associated fall in cardiovascular morbidity or mortality, is not an argument for thyroid hormone replacement.

\section{Exercise clinical judgement and do no harm}

In summary, the evidence for benefit of thyroid hormone treatment in $\mathrm{CH}$ is far from conclusive and we are unable to detect beforehand

1 Tunbridge WMG, Evered DC, Hall R, et al. The spectrum of thyroid disease in the community. The Whickham Survey. Clin Endocrinol 1977;7:481-93.

2 Davies PH, Franklyn JA, Daykin J \& Sheppard MC. The significance of TSH values measured in a sensitive assay in the follow-up of hyperthyroid patients treated with radioiodine. $\mathcal{F}$ Clin Endocrinol Metab 1992;74:1189-94.

3 Parle JV, Franklyn JA, Cross KW, Jones SC, Sheppard MC. Prevalence and follow-up of abnormal thyrotrophin (TSH) concentrations in the elderly in the United Kingdom. Clin Endocrinol 1991;34:77-83.

4 Bagchi N, Brown TR, Parish RF. Thyroid dysfunction in adults over age 55 years. A study in an urban US Commuadults over age 55 years. A study in an
nity. Arch Intern Med 1990;150:785-7.

5 Sawin CT, Castelli WP, Hershman JM. The aging thyroid Thyroid deficiency in the Framingham study. Arch Intern Med 1985;145:1386-8.

6 Lazarus JH, Burr ML, McGregor AM. The prevalence and progression of autoimmune thyroid disease in the elderly. Acta Endocrinol 1984;106:199-202.

7 Vanderpump MJ, Tunbridge WG, French JM, et al. The incidence of thyroid disorders in the community: A twentyyear follow-up of the Whickham Survey. Clin Endocrinol 1995;43:55-68.

8 Ingbar SH, Weiss M, Cushing GW, Kasper DL. A possible role for bacterial antigens in the pathogenesis of autoimmune thyroid disease. In: Pinchera A, Ingbar SH, McKenzie IM, Fenzi GF, eds, Thyroid autoimmunity. New York: JM, Fenzi GF, eds, Thyroid

9 Dayan CM. The natural history of autoimmune thyroiditis how normal is autoimmunity. Proc $R$ Coll Physicians Edinb 1996;26:419-33

10 Okayasu I, Hara Y, Nakamura K, Rose NR. Racial and agerelated differences in incidence and severity of focal autoimmune thyroiditis. Am F Clin Pathol 1994;101:698-702.

11 Mariotti S, Sansoni P, Barbesino G, et al. Thyroid and other organ-specific autoantibodies in healthy centenarians. Lancet 1992;339:1506-8.

12 McGregor AM, Weetman AP, Ratanachaiyavong S, Owen $\mathrm{GM}$, Ibberston HK, Hall R. Iodine: an influence on the development of autoimmune thyroid disease? In: Hall R, Kobberling J, eds, Thyroid disorders associated with iodine deficiency and excess. New York: Raven Press, 1985; iodine defi13 Szabolcs I, Podoba J, Feldkamp J, et al. Comparative screenSzabolcs I, Podoba J, Feldkamp J, et al. Comparative screen-
ing for thyroid disorders in old age in areas of iodine ing for thyroid disorders in old age in areas of iodine
deficiency, long-term iodine prophylaxis and abundan deficiency, long-term iodine prophylaxis
iodine intake. Clin Endocrinol 1997;47:87-92.

14 Laurberg P, Pedersen KM, Hreidarsson A, Sigfusson N, Iversen $\mathrm{E}$, Knudsen PR. Iodine intake and the pattern of those few ${ }^{19}$ that potentially might benefit. Also, suppressed TSH is common in individuals treated with thyroxine, ${ }^{26}$ and subclinical hyperthyroidism is not without morbidity. ${ }^{27}$ Instituting thyroxine treatment in $\mathrm{CH}$ will thus not simplify follow-up. As the progression to overt hypothyroidism is very slow, we believe that only those at high risk of progression ( $\geqslant 5 \%$ annually) to overt hypothyroidism should be routinely treated. These are females with mildly elevated TSH and positive TPO-Ab, females with TSH $>10 \mathrm{mU} / 1(80-90 \%$ are antibody positive), and males with elevated TSH regardless of antibody status. In other cases clinical judgement should prevail but follow-up every 2-5 years, at which both TSH and TPO-Ab should be measured, is probably adequate.

thyroid disorders: a comparative epidemiological study of thyroid abnormalities in the elderly in Iceland and in utland, Denmark. F Clin Endocrinol Metab 1998;83:765-9.

15 Kabadi UM, Cech R. Normal thyroxine and elevated thyrotropin concentrations: evolving hypothyroidism or persistent euthyroidism with reset thyrostat $f$ Endocrinol Invest 1997;20:319-26.

16 Konishi J, Kasagi K, Iida Y. Thyroid stimulation blocking antibodies - an overview. In: Nagataki S, Mori T, Torizuka $\mathrm{K}$, eds, 80 Years of Hashimoto disease. Amsterdam: Elsevier Science, 1993; pp 573-7.

17 Cooper DS, Halpern R, Wood LC. L-thyroxine therapy in subclinical hypothyroidism. A double-blind, placebocontrolled trial. Ann Intern Med 1984;101:18-24

18 Jansson S, Berg G, Lindstedt G, Michanek A, Nystrom E. Overweight - a common problem among women treated for hyperthyroidism. Postgrad Med F 1993;69:107-11.

19 Nystrom E, Caidahl K, Fager G, Wikkelso C, Lundberg P-A, Lindstedt G. A double-blind cross-over 12-month study of L-thyroxine treatment of women with 'subclinical' hypothyroidism. Clin Endocrinol 1988:29:63-75.

20 Carr D, McLeod DT, Parry G \& Thornes HM. Fine adjustment of thyroxine replacement dosage: comparison of the thyrotrophin releasing hormone test using a sensitive thyrotrophin assay with measurement with free thyroid hormones trophin assay with measurement with free thyroid hormon

21 Haggerty JJ, Garbutt JC, Evans DL, et al. Subclinica hypothyroidism: A review of neuropsychiatric aspects. Int $\mathcal{J}$ Psychiatry Med 1990;20:193-208.

22 Joffe RT, Levitt AJ. Major depression and subclinical (grade ) hypothyroidism. Psychoneuroendocrinology 1992;17:21521

23 Monzani F, Caraccio N, Siciliano G, Manca L, Murri L, Ferrannini E. Clinical and biochemical features of muscle dysfunction in subclinical hypothyroidism. $\mathcal{F}$ Clin Endocrinol Metab 1997;82:3315-8.

24 Ridgway EC, Cooper DS, Walker H. Peripheral responses to thyroid hormone before and after L-thyroxine therapy in patients with subclinical hypothyroidism. $₹$ Clin Endocrinol patients with subclinical

25 Tanis BC, Westendorp RJ, Smelt AM. Effect of thyroid substitution on hypercholesterolaemia in patients with subclinical hypothyroidism: A reanalysis of intervention studies. Clin Endocrinol 1996;44:643-9.

26 Parle JV, Franklyn JA, Sheppard MC. Thyroxine replacement therapy. Lancet 1991;337:171.

27 Sawin CT, Geller A, Wolf PA, et al. Low serum thyrotropin concentrations as a risk factor for atrial fibrillation in older persons. N Engl F Med 1994;331:1249-52. 